University of Nebraska - Lincoln

DigitalCommons@University of Nebraska - Lincoln

USDA National Wildlife Research Center - Staff Publications
U.S. Department of Agriculture: Animal and Plant Health Inspection Service

2-27-2019

\title{
Assessing public support for restrictions on transport of invasive wild pigs (Sus scrofa) in the United States
}

\author{
Meredith J. Grady \\ Colorado State University, Meredith.J.Grady@aphis.usda.gov \\ Erin E. Harper \\ United States Department of Agriculture Animal and Plant Health Inspection Service Wildlife Services \\ Keith M. Carlisle \\ United States Department of Agriculture Animal and Plant Health Inspection Service Wildlife Service \\ Karina H. Ernst \\ United States Department of Agriculture Animal and Plant Health Inspection Service Wildlife Service \\ Stephanie A. Shwiff \\ United States Department of Agriculture Animal and Plant Health Inspection Service Wildlife Services
}

Follow this and additional works at: https://digitalcommons.unl.edu/icwdm_usdanwrc

Part of the Life Sciences Commons

Grady, Meredith J.; Harper, Erin E.; Carlisle, Keith M.; Ernst, Karina H.; and Shwiff, Stephanie A., "Assessing public support for restrictions on transport of invasive wild pigs (Sus scrofa) in the United States" (2019). USDA National Wildlife Research Center - Staff Publications. 2239.

https://digitalcommons.unl.edu/icwdm_usdanwrc/2239

This Article is brought to you for free and open access by the U.S. Department of Agriculture: Animal and Plant Health Inspection Service at DigitalCommons@University of Nebraska - Lincoln. It has been accepted for inclusion in USDA National Wildlife Research Center - Staff Publications by an authorized administrator of DigitalCommons@University of Nebraska - Lincoln. 
Research article

\title{
Assessing public support for restrictions on transport of invasive wild pigs (Sus scrofa) in the United States
}

\author{
Meredith J. Grady ${ }^{\mathrm{a}, *}$, Erin E. Harper ${ }^{\mathrm{b}}$, Keith M. Carlisle ${ }^{\mathrm{b}}$, Karina H. Ernst ${ }^{\mathrm{b}}$, Stephanie A. Shwiff ${ }^{\mathrm{b}}$ \\ ${ }^{a}$ Department of Human Dimensions of Natural Resources, Colorado State University, Fort Collins, CO, 80523, USA \\ ${ }^{\mathrm{b}}$ National Wildlife Research Center, United States Department of Agriculture Animal and Plant Health Inspection Service Wildlife Services, Fort Collins, CO, 80521, USA
}

\section{A R T I C L E I N F O}

\section{Keywords:}

Sus scrofa

Transport restrictions

Hunter

Invasive species

Human dimensions

\begin{abstract}
A B S T R A C T
Wild pigs (Sus scrofa) are a non-native invasive species in the United States that cause significant economic loss, transmit disease, and inflict damage upon natural resources, agriculture, livestock, and property. Geographic distribution of wild pigs in the United States has nearly tripled since 1982, with anthropogenic influences playing a significant role in the expansion. In this regard, there is speculation that a driver of the expansion may be human-mediated movement of wild pigs to new areas for the purpose of sport hunting. In response, states have implemented a variety of wild pig control policies, including legal restrictions on their transport. The success of such policies depends, in part, on their level of public support, which in turn may be influenced by individuals' attitudes concerning wild pigs, their interest in maintaining wild pig populations (e.g., for sport hunting), and their knowledge and awareness of the threats wild pigs pose. Multiple regression was used to analyze data collected from a nationwide survey concerning attitudes toward wild pigs and policies that restrict their transport. Results indicate that a majority of individuals in the United States have negative attitudes toward wild pigs and support policies that restrict their transport and penalize transgressors. Consistent with other invasive species research, findings suggest that as knowledge and awareness of wild pigs increase, so too does support for policies restricting and penalizing transport of wild pigs. Contrary to previous studies, this research also finds that hunters are more likely to support restrictions on wild pig transport than are non-hunters. Overall, these findings suggest that legal restrictions on the transport of wild pigs, even in states with large hunter populations, enjoy broad public support and may help to curb the expansion of wild pig populations.
\end{abstract}

\section{Introduction}

\subsection{Wild pig background and management}

Wild pigs (Sus scrofa), also referred to as feral swine, are a nonnative invasive species in the United States that transmits disease and causes extensive damage to natural resources, agriculture, livestock, property, cultural sites, and people (USDA-APHIS, 2016). Vitousek et al. (1996) suggest that wild pigs may be the single most damaging introduced species to protected areas in the United States, and the International Union for Conservation of Nature includes wild pigs on its list of the 100 worst invasive species in the world (Corn and Jordan, 2017). Due to their destructive rooting and wallowing behaviors, wild pigs can have detrimental impacts on row crops, soil composition, water quality, and forest regeneration (Campbell and Long, 2009; Bevins et al., 2014). Furthermore, wild pigs carry a number of pathogens (e.g., pseudorabies, influenza A, brucellosis, and trichinella) that can infect humans, wildlife, and domestic animals (Bevins et al., 2014). Estimates of annual damage and control costs for wild pigs in the United States range from $\$ 800$ million (Elsey et al., 2012) to $\$ 1.5$ billion (Pimental, 2007). Regardless of the variation in these estimates, it is evident that wild pigs are associated with major ecological and economic losses.

Authority for managing wild pigs in the United States resides with the states, which have implemented a variety of policies to control the expansion of wild pig populations and their associated damages. These policies generally fall within three broad categories: hunting controls, eradication efforts, and precluding particular human activities associated with wild pigs (Centner and Shuman, 2015). With respect to the first, wild pigs are classified as a game species in a majority of states (e.g., Alabama, California, Hawaii), and even among states that prohibit the hunting of wild pigs on public land (e.g., Tennessee, Nebraska), relatively few restrict hunting the species on private property (SEAFWA-WHWG, 2016). The second category, eradication, represents

\footnotetext{
* Corresponding author. 4101 Laporte Avenue, Fort Collins, CO, 80521, USA

E-mail address: Meredith.J.Grady@aphis.usda.gov (M.J. Grady).
} 

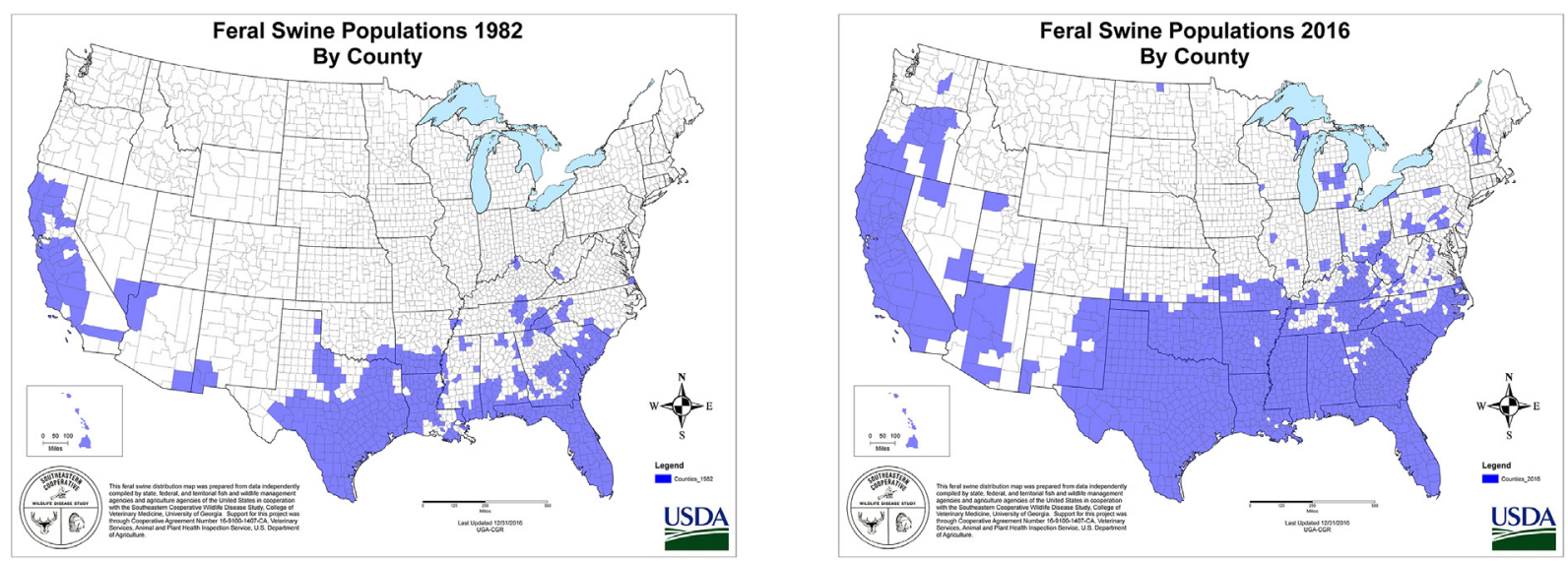

Fig. 1. Maps of wild pig population distribution by county in 1982 (left) and 2016 (right) (USDA-APHIS, 2018).
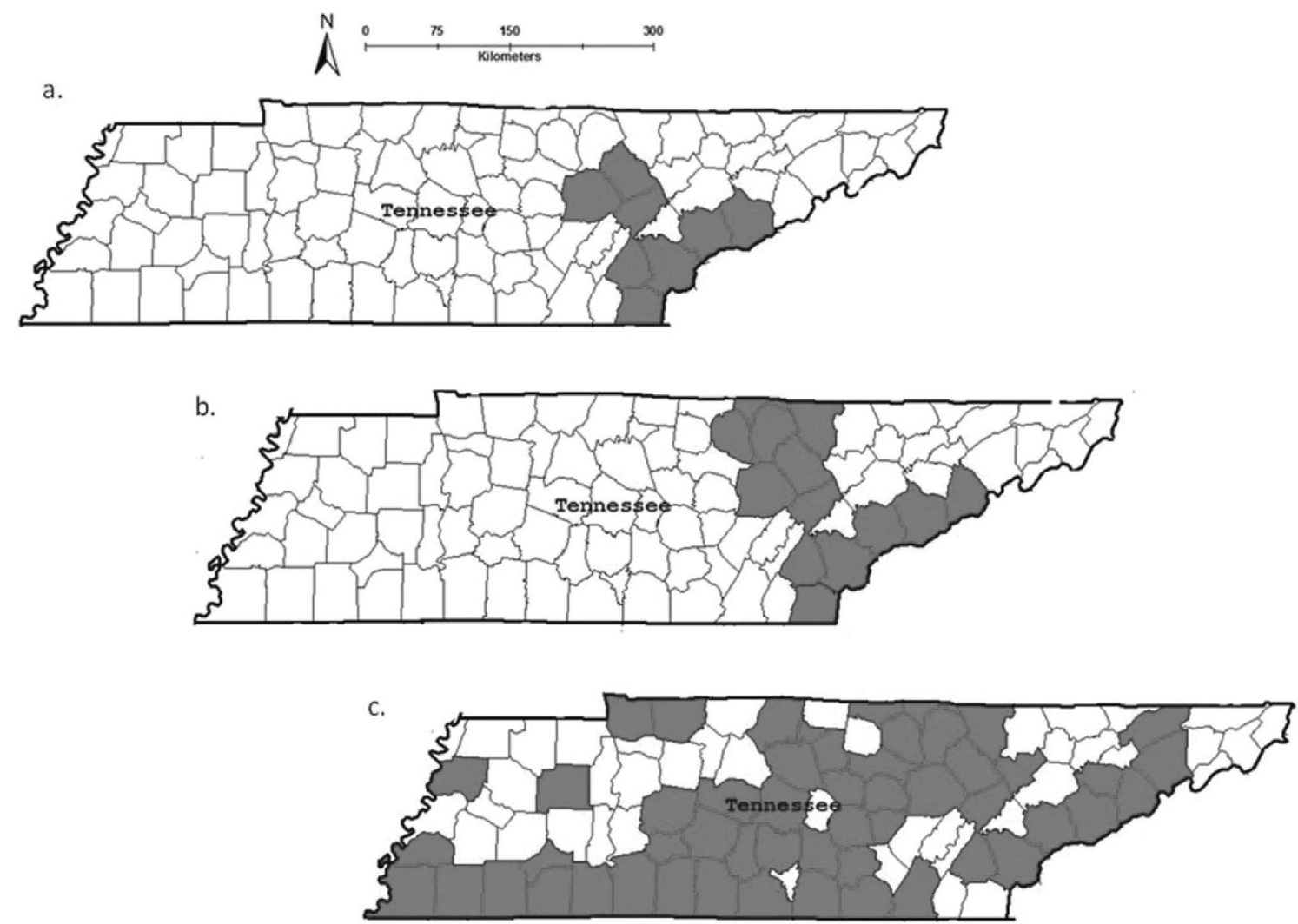

Fig. 2. The distribution of feral swine in Tennessee and known breeding populations (a) before 1950; (b) in 1988, prior to the open-season hunting program; and (c) in 2012, after the hunting program had ceased and sport hunting feral swine was outlawed in 2011. The data were provided by Daryl Ratajczak and Chuck Yoest of the Tennessee Wildlife Resources agency (Bevins et al., 2014).

the most extreme, and in many ways most challenging, management approach. The appropriateness and potential success of eradication efforts is partly dependent upon how many wild pigs are present in a state (Centner and Shuman, 2015). Those states with low numbers of wild pigs may be better able to prevent new introductions and to eradicate existing populations. Hunting controls and eradication efforts employ a variety of direct management techniques, including shooting, trapping, and toxicants, to remove wild pigs from the landscape. The final category, precluding activities, includes state policies that prohibit the transport of wild pigs, a focus of this research examined in greater detail below. Ultimately, many of the policies pursued by states have proven ineffectual, as demonstrated by the rapid spread of wild pig populations over the past several decades. (Centner and Shuman, 2015; Caudell et al., 2016; Caplenor et al., 2017). Between 1982 and 2016, the geographic area of wild pig distribution in the United States nearly tripled from $544,854 \mathrm{~km}^{2}$ to $1,675,618 \mathrm{~km}^{2}$, with the number of states reporting wild pig populations increasing from 18 to 35 during that time (Corn and Jordan, 2017) (Fig. 1).

\subsection{Wild pig transport}

One of the most significant risks for new introductions and range expansion is the transport of live wild pigs (SEAFWA-WHWG, 2016), as underscored by recent genetic research. A study by Hernández et al. (2018) in Florida revealed isolated genetic groupings of wild pigs and limited genetic exchange with other nearby wild pig populations, indicating relatively recent human-mediated translocations. Similarly, Tabak et al. (2017) found unnatural genetic clustering, significant 
population differentiation, and low rates of migration among wild pigs in California, suggesting that observed movement of the species resulted from human-mediated translocation. More broadly, McCann et al. (2018) examined the genetic structure of wild pig populations throughout the United States and concluded that translocations by humans were a key factor in long-range dispersal of the species.

The translocation of wild pigs has been attributed to the popularity of hunting the species for sport, especially transport of the animals to new areas without existing populations (Hutton et al., 2006; Bevins et al., 2014; Caudell et al., 2016). Although hunting may provide a measure of population control, it may also stimulate interest in maintaining or establishing populations for hunting activities (Mapston, 2004; SEAFWA-WHWG, 2016; Caudell et al., 2016). This is supported by the findings of Tabak et al. (2017), who found that movement of wild pigs was predicted not only by the number of domestic pig farms and the amount of public land in an area, but also by the number of captive game hunting farms, the number of wild pigs harvested by hunters, and the number of game outfitters in an area (Tabak et al., 2017). Wild pig management efforts in Tennessee are illustrative of the apparent link between wild pig hunting, transport, and ultimately, range expansion (Fig. 2). Through the 1980s, wild pig populations in Tennessee existed in a relatively small number of counties in the eastern region of the state, with limited range expansion (Bevins et al., 2014). In 1999, state regulators implemented a new policy designed to curb wild pig populations: a statewide open-season hunting program for wild pigs designed to increase participation in wild pig hunting (ibid.). In the decade following implementation of the new policy, wild pig populations spread to nearly 70 counties throughout the state, a range expansion that has been attributed to the transport of wild pigs by hunters (ibid.). Faced with this surprising dilemma, Tennessee lawmakers outlawed sport hunting of wild pigs in 2011 in order to reduce incentives for wild pig transport.

On account of the association between wild pig transport and range expansion, the United States Department of Agriculture recommends that states prohibit the practice (2016). To date, however, only roughly half of the states have done so. Given the critical importance of preventing wild pig transport, this research explores potential barriers and opportunities for the implementation of such policies. In particular, we examine public attitudes towards wild pigs and support for legal restrictions on wild pig transport. Because the control of wild pigs requires the participation and cooperation of private landowners and other members of the public, it is critical that state decision makers understand the public's attitudes towards a potential control policy before implementing it (Harper et al., 2016). In this sense, managing an invasive species like wild pigs is as much of a social issue as an ecological one (Bremner and Park, 2007). We note that previous research has focused primarily on landowner or farmer perspectives towards wild pigs (Harper et al., 2016; Caplenor et al., 2017). To the best of our knowledge, this is the first nationwide study of the general public's attitudes towards wild pigs and restrictions on their transport. This research, thus, provides new and important information to inform the efforts of state decision makers and resource managers.

\subsection{Theoretical framework and research objectives}

This research is grounded in the widely-applied cognitive hierarchy model (Homer and Kahle, 1988), which posits that individual behavior flows from a series of interrelated cognitions, such as values and attitudes (Teel and Manfredo, 2010). These cognitions and behaviors are ordered in hierarchical fashion (Vaske and Donnelly, 1999). At the base of the hierarchy are values, which are foundational cognitions that are relatively fewer in number and slower to change (Vaske and Donnelly, 1999; Teel and Manfredo, 2010). They represent an individual's overarching beliefs, and they direct or influence an individual's attitudes (Manfredo, 2008). Attitudes, defined as positive or negative evaluations of a general or specific object (Whittaker et al., 2006), are the most commonly investigated cognition in the field of human dimensions of natural resources (Manfredo et al., 2004). Attitude studies are popular, in part, because they provide information that may help predict behaviors (Manfredo et al., 2004). In this regard, attitudes are generally believed to be a proximate cause of behaviors, though other factors, such as context and attitude salience, may determine the extent to which attitudes translate to specific behaviors (Manfredo, 2008). Importantly, attitudes are more susceptible to change over time than are values, and changes in attitudes may result in changes in behavior (Manfredo et al., 2009; Caplenor et al., 2017). Education and outreach efforts may therefore prove fruitful in influencing attitudes towards a particular policy or activity and bringing about desired behaviors.

This research examines public attitudes towards wild pigs and policies that restrict their transport. In doing so, it provides valuable information for resource managers concerned with prioritizing various wild pig control strategies and targeting education and outreach efforts. In addition, this work builds upon previous invasive species research that examines not only attitudes and other cognitive concepts, but also the association of species-specific knowledge and awareness and various socio-demographic factors relative to an individual's attitudes towards policies to control an invasive species (Aipanjiguly et al., 2003; Bremner and Park, 2007; Sharp et al., 2011; Harper et al., 2016; Caplenor et al., 2017). The overall objectives of this study are to understand public attitudes toward wild pigs, examine what factors may influence support for legal restrictions on wild pig transport, and determine if hunting experience can be used to predict support for such restrictions. We seek to answer the following questions:

1. How are attitudes toward wild pigs, awareness of wild pigs in the United States, and knowledge of wild pig biology and ecology associated with support for wild pig transport restrictions?

2. How is participation in hunting activities associated with support for wild pig transport restrictions?

3. How are other socio-demographic factors associated with support for wild pig transport restrictions?

\section{Methods}

\subsection{Sampling and data collection}

We collected data for this study using a nationwide mail survey with an online response option. Our sample, obtained from infoUSA ${ }^{\circ}$, was random and stratified to include 200 rural residents and 200 urban residents from each of the 50 states in the United States $(20,000$ individuals in total). A pre-notification post card was mailed, followed one week later by a questionnaire packet (cover letter, questionnaire, and stamped return envelope). A thank you/reminder postcard was subsequently mailed, followed by a second questionnaire packet, followed by a final thank you/reminder postcard with an online response option. All versions of the questionnaire included the same questions. The online questionnaire was provided through SurveyMonkey".

\subsection{Dependent variables}

Five belief/attitudinal statements were presented in the questionnaire to assess support for policies that would restrict the transport of wild pigs (see Table 2 in section 3 below). Respondents were asked to agree or disagree on a five-point Likert-like scale from "strongly disagree" (1) to "strongly agree" (5) with an option to choose "does not apply" (6). The "agree" or "disagree" responses for each management action were condensed into a dichotomous variable for purposes of the multiple regression, and each statement was analyzed independently. "Support" for legal transport restrictions and penalties was determined by whether or not a respondent's answer (agree or disagree) aligned with policies restricting movement of wild pigs. For example, if the respondent selected "strongly disagree" or "disagree" in response to the 
Table 1

Belief/attitudinal statements about wild pigs.

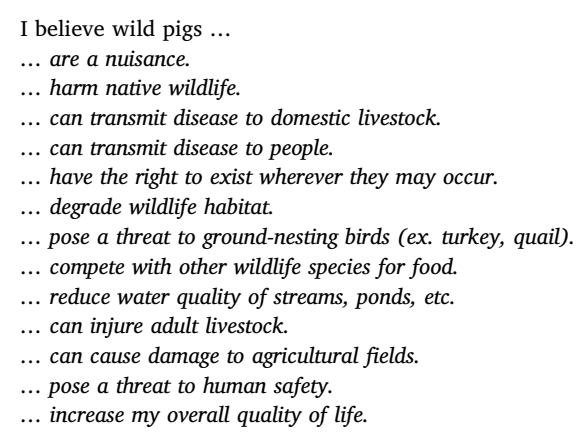

statement "Wild pigs should be allowed to be transported anywhere in the U.S. without restrictions," we considered that support for restrictions on transport of wild pigs. If the respondent selected "strongly agree" or "agree" to the statement "There should be penalties for illegally transporting wild pigs within my state," this was also considered to be support for restrictions on transport. Coding the data in this manner allowed for more intuitive interpretation of regression results.

\subsection{Independent variables}

The independent variables in this study consisted of hunting participation, attitudes towards wild pigs, awareness of the existence of wild pigs in the United States, general knowledge about wild pigs, and various socio-demographic factors. Hunting participation was determined by asking whether the respondent had ever hunted. Although the questionnaire also asked respondents whether they had specifically hunted for wild pigs, our sample size of those who responded affirmatively was not large enough for statistically significant comparisons.

To measure attitudes towards wild pigs, thirteen belief/attitudinal statements were included in the questionnaire (Table 1). These statements were measured on a five-point scale ranging from strongly disagree (1) to strongly agree (5). Responses to all thirteen belief statements were averaged into a single variable representing a positive or negative attitude towards wild pigs.

To determine awareness of wild pigs, respondents were asked if they had heard of wild pigs in the United States before receiving the questionnaire. To determine knowledge of wild pigs, respondents were presented with five statements (e.g., "Wild pigs are native to the United States.") and were asked to select "True," "False," or "Unsure." These five statements were combined to generate an overall knowledge score on a scale from one to five, reflecting how many correct responses the respondent selected.

With respect to socio-demographic factors, respondents were asked to identify as male, female, transgender male, transgender female, genderqueer, or they could choose "prefer not to answer." Gender was categorized into three groups: "male" (2), "female" (1), and "other" (0), which includes all other responses. Respondents were also asked to write in their age, but for analysis, age was categorized into seven groups (18-35, 36-45, 46-55, 56-65, 66-75, 76-85, 86-100). Surveys from respondents under the age of 18 were disregarded. Household income was a categorical variable with 12 response categories, ranging from (a) less than $\$ 10,000$ to (1) $\$ 250,000$ and higher. Education level was also a categorical variable with eight response categories: (a) some high school, (b) high school/GED, (c) some college, (d) associate's degree, (e) bachelor's degree, (f) master's degree, (g) doctorate, and (h) vocational/professional certification.

Respondents were also asked to identify the type of area where they were raised as a youth and the type of area where they live now. Both variables were categorical with eight response categories: (a) farm or rural area, (b) small town/village with less than 5,000 people, (c) town with 5,000-9,999 people, (d) town with 10,000-24,999, (e) small city with 25,000-49,999, (f) city with 50,000-99,999, (g) city with $100,000-249,999$, and (h) large city with 250,000 people or more.

\subsection{Analysis}

We analyzed the data using R, a free software for statistical computing. Survey results were analyzed to obtain descriptive statistics and to examine factors that may be associated with support for transport restrictions on wild pigs. To understand the association of the independent variables with each of the five dependent variables, we used multiple regression.

\section{Results and discussion}

\subsection{Return rate}

Of the 20,000 surveys sent out, 2,226 were returned for a response rate of $11.1 \%$. Although our response rate was fairly low, our sample size of 2,226 individuals was well above the estimated minimum return sample size needed $(\mathrm{n}=384)$ according to Cochran's sample size formula (Cochran, 1977; Barlett et al., 2001). Sample size estimations were calculated using a population size of 325.7 million people in the United States, a 95\% confidence level, and a 5\% margin of error. A nonresponse bias check was not conducted due to time and resource limitations; however, demographic characteristics of our sample were roughly similar to that of the United States population, as described below.

\subsection{Demographic statistics}

The majority of respondents were male (56\%), between the ages of 18 and 64 (86\%), and white (89\%). An overwhelming majority of respondents had completed a high school education or higher (97\%), and over half $(57 \%)$ had completed a bachelor's degree or higher. The median reported annual household income was between $\$ 50,000$ and $\$ 74,999$ before taxes (accounting for $21 \%$ of respondents). The main demographic characteristics were roughly similar between the sample and the general population of the United States according to the United States Census Bureau QuickFacts (2016). For example, the United States general population is approximately half male and half female, $62 \%$ of the population is between the ages of 18 and 64 , and $77 \%$ is white. Furthermore, $87 \%$ of the general population has completed a high school education or higher, compared to $97 \%$ of respondents in our survey. Finally, the median household income for the United States general population in 2016 was $\$ 55,322$, which also falls within the median range of our survey sample.

Respondents were asked to select where they were raised as a youth and where they currently live, with options ranging over an eight-point scale from farm or rural area to large city. We asked about the type of area where a person was raised because previous studies have shown that a person's exposure to nature and rural areas may shape their attitudes towards wildlife later in life (Heberlein and Ericsson, 2005). For example, people who currently live in an urban area but were raised in a rural area may be more likely to participate in hunting because of the positive attitudes towards hunting in many rural areas. Of the respondents, $67 \%$ indicated they were raised in a town of less than 25,000 people and $33 \%$ indicated a city with 25,000 people or more, with the median being a farm or rural area (34\%). When asked where they live now, $68 \%$ selected a town of less than 25,000 people and $32 \%$ selected a city with 25,000 people or more, with the median being a farm or rural area (32\%).

Participation in hunting was a variable of particular interest in our study, and we found that over half of all respondents (58\%) had previously hunted. As noted above, the number of respondents who hunted specifically for wild pigs $(7 \%)$ was too low to allow for statistical 
comparison with other groups. We therefore did not differentiate between hunting types in our analysis, but rather grouped all hunters into a single category for comparison against those who do not hunt (42\%).

\subsection{Attitude, awareness, and knowledge}

Our results show that over half of the respondents (56\%) had an overall negative attitude towards wild pigs based on the thirteen belief statements combined. This finding is consistent with previous research on invasive wild pigs (Adams et al., 2005; Li et al., 2010; Harper et al., 2016; Caplenor et al., 2017). Hunters in our sample had a more negative attitude towards wild pigs than did non-hunters. For example, $70 \%$ of respondents who had hunted agreed with the statement "I believe wild pigs are a nuisance," compared to only $43 \%$ of non-hunters. Furthermore, $71 \%$ of hunters responded that they believe wild pigs harm native wildlife, degrade wildlife habitat, pose a threat to ground-nesting birds, and compete with other wildlife species for food, compared to only $48 \%$ of non-hunters. The majority of hunters and non-hunters agreed, however, that wild pigs can cause damage to agricultural fields ( $85 \%$ and $64 \%$ respectively). Overall, $66 \%$ of hunters had a negative attitude towards wild pigs, compared to $46 \%$ of non-hunters. A possible explanation for hunters' more negative attitudes towards wild pigs is that, as discussed below, they have a better understanding of the negative impacts wild pigs can have on wildlife and habitat. In particular, wild pigs can adversely affect other game species targeted by hunters (Beach, 1993; Tolleson et al., 1993; Taylor and Hellgren, 1997).

In terms of wild pig awareness, $89 \%$ of respondents had heard of wild pigs in the United States before receiving the questionnaire. Hunters had greater awareness of wild pigs (i.e., selected "yes" indicating they had heard of wild pigs in the United States) than nonhunters, though a large majority of both groups had heard of wild pigs before receiving the questionnaire (95\% of hunters and; $81 \%$ of nonhunters). We also found that hunters in our sample tended to have more knowledge about the species than non-hunters based on the five true or false statements about wild pig biology and ecology. Half (50\%) of nonhunter respondents failed to answer any of the five knowledge questions correctly, whereas $75 \%$ of hunters answered one or more of the knowledge questions correctly. Our findings generally comport with Ericsson and Heberlein (2003), who, in the case of wolves, found that hunters had more knowledge about, and more negative attitudes towards, the species than did non-hunters. In our study, the mean knowledge score for all respondents combined was 1.8, meaning the average number of correct responses was 1.8 out of 5 .

\subsection{Wild pig transport restrictions}

The relative frequencies of responses to the dependent variable questions about restrictions on the transport of wild pigs are presented in Table 2. The median responses from both hunters and non-hunters generally aligned in support of transport restrictions, though a higher percentage of hunters supported them. The statement with the most variation between the two groups in our sample was the question about allowing wild pigs to be transported if a veterinarian verifies that the animals are clean of diseases, with which $52 \%$ of hunters disagreed
(19\% agreed) and only 33\% of non-hunters disagreed (26\% agreed). This likely reflects our findings that hunters generally have greater knowledge of the non-disease risks associated with wild pigs (e.g., ecological risks) than do non-hunters and also have more negative attitudes towards wild pigs. They may therefore be more likely to support transport restrictions, even if the animals are disease-free.

\subsection{Multiple regression}

Results from the multiple regression models presented in Table 3 explain how independent variables are associated with each of the five statements concerning transport of wild pigs. The first three models (disagree with transported, enforced, and clean) examine more general statements regarding wild pig transport restrictions. The last two models (penalties out and penalties in) dig deeper into statements regarding penalties for moving wild pigs within and outside of state boundaries. Seven of the ten independent variables included in the models were significant for at least one of the dependent variable statements. Participation in hunting was only significant for two of the five statements, and the significant positive results suggest that if a person has hunted, they will be more likely to support legal restrictions on the transport of wild pigs. Attitude was highly significant and positive for all of the five statements. In other words, if a person has a negative attitude towards wild pigs, they are more likely to support regulatory restrictions on transportation. In addition, the level of knowledge about wild pigs was significant and positive for all five statements. Awareness of wild pigs was significant and positive for four out of the five statements. Of the demographic variables within the models, gender, income, and type of place where the respondent was raised as a youth were all significant for at least one of statements.

\subsubsection{Disagree with transport}

The first model (disagree with transport) concerns the question of whether unrestricted transport of wild pigs throughout the country should be allowed. There was a significant positive correlation between hunting and support for restricting the transport of wild pigs. Previous studies have found that hunters may prefer robust numbers of wild pigs to support hunting activities (Mapston, 2004; Plasters et al., 2013) and may be less likely to support state efforts to control wild pig populations (Caplenor et al., 2017). However, our results suggest that hunters are more likely to support restrictions on the transport of wild pigs than are non-hunters. Most hunters in our study (71\%) responded that they believe wild pigs negatively impact wildlife and habitat. We hypothesize that this may lead them to support restrictions on wild pig transport because of the adverse impact the species has on other game species. We also acknowledge that our findings may reflect that a relatively low percentage of hunters in our study hunt for wild pigs and that hunters who target wild pigs may be less supportive of transport restrictions.

Other variables that were significantly and positively correlated with support for wild pig transport restrictions include (i) negative attitude towards wild pigs, (ii) greater awareness of the presence of wild pigs in the United States, and (iii) greater knowledge about wild pig biology and ecology. These findings suggest that support for wild pig transport restrictions may increase as individuals become more

Table 2

Responses to belief/attitudinal statements about the transport of wild pigs.

\begin{tabular}{|c|c|c|c|c|c|}
\hline Variable Code & Statement & Disagree $\%$ & Agree $\%$ & Neutral \% & N/A \% \\
\hline Disagree with Transport & Wild pigs should be allowed to be transported anywhere in the U.S. without restrictions. & 72 & 3 & 23 & 2 \\
\hline Enforced & Restrictions on the transportation of wild pigs from my state to other states are strictly enforced. & 9 & 21 & 53 & 17 \\
\hline Clean & $\begin{array}{l}\text { Wild pigs should be allowed to be transported anywhere in the U.S. after a veterinarian verifies they are clean of } \\
\text { any transmittable disease. }\end{array}$ & 44 & 22 & 31 & 3 \\
\hline Penalties Out & There should be penalties for illegally transporting wild pigs from my state to other states. & 4 & 61 & 24 & 11 \\
\hline Penalties In & There should be penalties for illegally transporting wild pigs within my state. & 5 & 58 & 27 & 10 \\
\hline
\end{tabular}

Note: Data originally on 6-point scale. Strongly Agree/Strongly Disagree and Agree/Disagree combined into Agree/Disagree in table. 
Table 3

Results from multiple regression (see Table 2 for full statements associated with dependent variable column headers).

\begin{tabular}{|c|c|c|c|c|c|}
\hline Dependent Variables & Disagree with Transport ${ }^{\mathrm{a}}$ & Enforced & Clean & Penalties Out & Penalties In \\
\hline Independent Variables & Coefficient (Std. Error) & & & & \\
\hline Hunted & $0.195^{* *}(0.083)$ & $0.108(0.093)$ & $0.162^{* *}(0.79)$ & $0.053(0.083)$ & $-0.002(0.081)$ \\
\hline Attitude & $0.723 * * *(0.075)$ & $0.412 * * *(0.075)$ & $0.823^{* * *}(0.069)$ & $0.540 * * *(0.072)$ & $0.590 * * *(0.071)$ \\
\hline Knowledge & $0.105^{* * *}(0.027)$ & $0.063^{* *}(0.028)$ & $0.041 *(0.024)$ & $0.093^{* * *}(0.026)$ & $0.054 * *(0.025)$ \\
\hline Awareness & $0.241 * *(0.117)$ & $0.099(0.157)$ & $0.241 *(0.133)$ & $0.262 * *(0.119)$ & $0.290 * *(0.119)$ \\
\hline Gender & $0.031(0.078)$ & $0.220 * *(0.087)$ & $0.074(0.074)$ & $0.122(0.077)$ & $0.080(0.075)$ \\
\hline Age & $0.001(0.025)$ & $-0.010(0.027)$ & $0.013(0.023)$ & $-0.015(0.024)$ & $-0.026(0.024)$ \\
\hline Income & $0.010(0.018)$ & $-0.059^{* * *}(0.020)$ & $0.040 * *(0.017)$ & $-0.035 *(0.018)$ & $-0.023(0.018)$ \\
\hline Raised & $-0.040^{* *}(0.017)$ & $-0.033 *(0.018)$ & $-0.018(0.016)$ & $0.009(0.017)$ & $0.023(0.016)$ \\
\hline Live & $-0.012(0.017)$ & $-0.000(0.018)$ & $-0.016(0.016)$ & $-0.006(0.017)$ & $-0.005(0.017)$ \\
\hline Education & $-0.004(0.019)$ & $0.004(0.021)$ & $0.008(0.018)$ & $0.027(0.019)$ & $0.005(0.018)$ \\
\hline
\end{tabular}

$* * * \mathrm{p} \leq 0.001, * * \mathrm{p} \leq 0.01, * \mathrm{p} \leq 0.1$.

a This regression is testing the extent to which an individual would disagree with the transport statement (i.e., would support restrictions on transport of wild pigs).

cognizant of the risks associated with wild pigs. Indeed, previous research has found that knowledge and awareness about a species have been shown to influence support for policies to control the species (Sharp et al., 2011). We also found that the area where a person was raised (i.e., rural/small town or larger city) was significantly and negatively correlated with support for wild pig transport restrictions. Individuals raised in more rural settings (including small towns) were more likely to support restrictions on wild pig transport than were individuals raised in more urban areas. As noted above, previous studies have also shown that individuals' attitudes towards wildlife may be influenced by the amount of exposure they have had to nature and rural areas (Heberlein and Ericsson, 2005). As rural areas are often more dependent on agriculture, we speculate that individuals who have lived in rural areas may be more familiar with the damages wild pigs can inflict.

\subsubsection{Enforced}

The enforced model concerns whether respondents believe current restrictions on inter-state transportation are strictly enforced. Respondents were more likely to agree that restrictions are enforced if they had a negative attitude towards wild pigs, were knowledgeable about wild pig biology and ecology, identified as male, had lower incomes, and were raised in a rural area or small town. Annual household income was significantly and negatively correlated with the enforcement dependent variable; those with lower household incomes were more likely to agree that restrictions on wild pig transport are strictly enforced. Furthermore, gender is a significant variable, with males being more likely to agree that restrictions on wild pig transport are strictly enforced. We note that despite the significance of the aforementioned variables, $71 \%$ of respondents were either neutral or unsure if restrictions on wild pig transportation are strictly enforced in their state. This not a surprising finding, as we would expect a large percentage of the public (particularly those who do not hunt for wild pigs) to lack the knowledge and experience to answer this question with any degree of certainty.

\subsubsection{Clean}

The third model (clean) concerns whether a respondent believes unrestricted transport of wild pigs should be allowed if a veterinarian verifies that the animals are clean of any diseases. For purposes of our analysis, if a respondent disagreed that unrestricted transport of wild pigs should be allowed under this circumstance, we classified the response as support for restrictions on wild pig transport (i.e., if the respondent disagreed, we assumed he or she felt that wild pigs should not be transported even if a veterinarian clears the animal). We found that respondents were more likely to support regulatory restrictions on transportation, even if the animal was verified clean of diseases, if they had hunted before, had a negative attitude towards wild pigs, were knowledgeable about wild pig biology and ecology, were aware of the existence of wild pigs in the United States, and had higher income. As with our earlier findings, respondents with greater wild pig knowledge and awareness (including hunters) were more supportive of strict controls on wild pig transport. In this case, respondents with greater knowledge and awareness may better understand that disease transmission is but one of many risks posed by wild pigs.

\subsubsection{Penalties out and penalties In}

The penalties out model concerns whether respondents believe there should be penalties for illegally transporting wild pigs from their state of residence to other states, and the penalties in model concerns whether respondents believe there should be penalties for illegally transporting wild pigs within their state of residence. The variables of significance for both of these models were the same, so we address them together here. As in prior models, attitude, knowledge, and awareness are all strong predictors of support for penalties. Again, this suggests that if a person understands the risks associated with wild pigs, they likely prefer stronger restrictions on wild pig transport. Respondents with lower household incomes were also more likely to support penalties for the transport of wild pigs. We speculate that it may be the case that those with lower incomes are more vulnerable to wild pig damage and, hence, more in favor of strict controls on wild pig transport and penalties.

\section{Conclusions}

Results indicate that the majority of Americans hold negative attitudes toward wild pigs and support legal restrictions and penalties on transport of the species. This finding is consistent with previous, more geographically restricted, studies concerning attitudes towards wild pigs (Harper et al., 2016; Caplenor et al., 2017). Our results also show that knowledge and awareness of wild pigs are significantly and positively correlated with support for transport restrictions on wild pigs. This suggests that continuing education and outreach efforts could influence attitudes towards wild pigs and, in turn, increase public support for transport restrictions. Caplenor et al. (2017) suggest that peer-topeer efforts may be useful in public education and outreach on account of their finding that peer expectations exert a strong influence on support for control of wild pigs. Hunters may offer an influential and untapped channel for educating other hunters on the risks associated with wild pig transport.

Contrary to previous studies, we found that hunters are more likely to support restrictions and penalties on wild pig transport than nonhunters. This likely reflects our findings that, compared to non-hunters, hunters have more negative attitudes towards wild pigs and greater awareness and knowledge of the species. With greater awareness and knowledge, hunters may better appreciate the risks posed by wild pigs. Most hunters from our survey (71\%) said that they believe wild pigs negatively impact wildlife and habitat, which may explain their higher 
level of support for transport restrictions - particularly if they associate wild pigs with detrimental impacts on other game species, such as ground-nesting birds and the young of larger mammals (e.g., whitetailed deer [Odocoileus virginianus]) (Beach, 1993; Tolleson et al., 1993; Taylor and Hellgren, 1997). These findings suggest that the presence of a large population of hunters should not necessarily be taken as an indication that there will be insufficient public support for restrictions on the transport of wild pigs. Whether or not hunters will support such restrictions may depend, in part, on their desire to hunt wild pigs. Indeed, a limitation of our study was that we did not have a large enough sample of wild pig hunters to allow for comparison with other hunters. Additional research specifically targeting wild pig hunters could provide valuable insight on their attitudes towards wild pig control and their motivations for hunting and transporting wild pigs.

Finally, we note that due to the high reproductive capacity and adaptability of wild pigs (Bevins et al., 2014), it only takes a few individuals transporting the animals to establish a new population where one previously did not exist. This is a major challenge for wildlife managers and enforcement officers, and the issue highlights the importance of increasing our understanding of motivations for wild pig transport and barriers to enforcement and compliance. Ultimately, controlling the expansion of wild pig populations requires greater insight into the many factors (including attitudes) that influence stakeholder behaviors and contribute to the complex social dilemmas surrounding the management and use of wild pig populations.

\section{Acknowledgements}

We would like to thank the United States Department of Agriculture Animal and Plant Health Inspection Service Wildlife Services National Feral Swine Damage Management Program and National Wildlife Research Center for making research at this scale possible. A special thanks to Mississippi State University for assisting with survey development and administration. Additional support was provided by Colorado State University. This work was funded by the National Feral Swine Damage Management Program.

\section{Appendix A. Supplementary data}

Supplementary data to this article can be found online at https:// doi.org/10.1016/j.jenvman.2019.02.107.

\section{References}

Adams, C.E., Higginbotham, B.J., Rollins, D., Taylor, R.B., Skiles, R., Mapston, M., Turman, S., 2005. Regional perspectives and opportunities for feral hog management in Texas. Wildl. Soc. Bull. 33 (4), 1312-1320.

Aipanjiguly, S., Jacobson, S.K., Flamm, R., 2003. Conserving manatees: knowledge, attitudes, and intentions of boaters in Tampa Bay, Florida. Conserv. Biol. 17 (4), 1098-1105.

Barlett, J.E., Kotrlik, J.W., Higgins, C.C., 2001. Organizational research: determining appropriate sample size in survey research. Inf. Technol. Learn. Perform. J. 19 (1), 43.

Beach, R., 1993. Depredation Problems Involving Feral Hogs. Feral Swine: A Compendium for Resource Managers. Texas Agricultural Extension Service, Kerrville, TX, USA, pp. 67-75.

Bevins, S.N., Pedersen, K., Lutman, M.W., Gidlewski, T., Deliberto, T.J., 2014. Consequences associated with the recent range expansion of nonnative feral swine. Bioscience 64 (4), 291-299.

Bremner, A., Park, K., 2007. Public attitudes to the management of invasive non-native species in Scotland. Biol. Conserv. 139 (3-4), 306-314.

Campbell, T.A., Long, D.B., 2009. Feral swine damage and damage management in forested ecosystems. For. Ecol. Manag. 257 (12), 2319-2326.

Centner, T.J., Shuman, R.M., 2015. Governmental provisions to manage and eradicate feral swine in areas of the United States. Ambio 44 (2), 121-130.

Caplenor, C.A., Poudyal, N.C., Muller, L.I., Yoest, C., 2017. Assessing landowners' attitudes toward wild hogs and support for control options. J. Environ. Manag. 201, 45-51.

Caudell, J.N., Dowell, E., Welch, K., 2016. Economic utility for the anthropogenic spread of wild hogs. Hum. Wildl. Interact. 10 (2), 230.

Cochran, W.G., 1977. Sampling Techniques, 3d Ed. Wiley.

Corn, J.L., Jordan, T.R., 2017. Development of the national feral swine map, 1982-2016. Wildl. Soc. Bull. 41 (4), 758-763.

Elsey, R.M., Mouton Jr., E.C., Kinler, N., 2012. Effects of feral swine (Sus scrofa) on alligator (Alligator mississippiensis) nests in Louisiana. SE. Nat. 11 (2), 205-218.

Ericsson, G., Heberlein, T.A., 2003. Attitudes of hunters, locals, and the general public in Sweden now that the wolves are back. Biol. Conserv. 111 (2), 149-159.

Harper, E.E., Miller, C.A., Vaske, J.J., Mengak, M.T., Bruno, S., 2016. Stakeholder attitudes and beliefs toward wild pigs in Georgia and Illinois. Wildl. Soc. Bull. 40 (2), 269-273.

Heberlein, T.A., Ericsson, G., 2005. Ties to the countryside: accounting for urbanites attitudes toward hunting, wolves, and wildlife. Hum. Dimens. Wildl. 10 (3), 213-227.

Hernández, F.A., Parker, B.M., Pylant, C.L., Smyser, T.J., Piaggio, A.J., Lance, S.L., et al., 2018. Invasion ecology of wild pigs (Sus scrofa) in Florida, USA: the role of humans in the expansion and colonization of an invasive wild ungulate. Biol. Invasions 1-16.

Homer, P.M., Kahle, L.R., 1988. A structural equation test of the value-attitude-behavio hierarchy. J. Pers. Soc. Psychol. 54 (4), 638.

Hutton, T., DeLiberto, T., Owen, S., Morrison, B., 2006. Disease Risks Associated with Increasing Feral Swine Numbers and Distribution in the United States.

Li, L., Wang, J., Shi, J., Wang, Y., Liu, W., Xu, X., 2010. Factors influencing local people's attitudes towards wild boar in Taohongling National Nature Reserve of Jiangxi Province, China. Procedia Environ. Sci. 2, 1846-1856.

Manfredo, M.J., 2008. Who Cares about Wildlife? Social Science Concepts for Exploring Human-Wildlife Relationships and Conservation Issues. Springer, New York, NY.

Manfredo, M.J., Teel, T.L., Bright, A.D., 2004. Application of the concepts of values and attitudes in human dimensions of natural resources research. In: Manfredo, M.J., Vaske, J.J., Field, D., Brown, P.J. (Eds.), Society and Natural Resources: A Summary of Knowledge Prepared for the $10^{\text {th }}$ International Symposium on Society and Natural Resources. Modern Litho, Jefferson, MO, pp. 271-282.

Manfredo, M.J., Teel, T.L., Henry, K.L., 2009. Linking society and environment: a multilevel model of shifting wildlife value orientations in the western United States. Soc. Sci. Q. 90 (2), 407-427.

McCann, B.E., Smyser, T.J., Schmit, B.S., Newman, R.A., Piaggio, A.J., Malek, M.J., et al., 2018. Molecular population structure for feral swine in the United States. J. Wildl. Manag. 82 (4), 821-832.

Mapston, M., 2004. Feral Hogs in Texas. Texas Cooperative Extension Service B-6149.

Pimental, D., 2007. Environmental and Economic Costs of Vertebrate Species Invasions into the United States.

Plasters, B.C., Hicks, C., Gates, R., Titchenell, M., 2013. Feral Swine in Ohio: Managing Damage and Conflicts. Ohio State University Extension W-26-13. Ohio State University, Columbus, pp. 1-6.

SEAFWA-WHWG Annual State Summary Report, 2016. Southeastern Association of Fish and Wildlife Agencies. Wild Hog Working Group.

Sharp, R.L., Larson, L.R., Green, G.T., 2011. Factors influencing public preferences for invasive alien species management. Biol. Conserv. 144 (8), 2097-2104.

Tabak, M.A., Piaggio, A.J., Miller, R.S., Sweitzer, R.A., Ernest, H.B., 2017. Anthropogenic factors predict movement of an invasive species. Ecosphere 8 (6).

Taylor, R.B., Hellgren, E.C., 1997. Diet of feral hogs in the western South Texas Plains. SW. Nat. 33-39.

Teel, T.L., Manfredo, M.J., 2010. Understanding the diversity of public interests in wildlife conservation. Conserv. Biol. 24 (1), 128-139.

Tolleson, D., Rollins, D., Pinchak, W., Ivy, M., Hierman, A., 1993. In: Hanselka, C.W., Cadenhead, J.F. (Eds.), Impact of Feral Hogs on Ground-Nesting Gamebirds. Feral Swine: a Compendium for Resource Managers. Texas Agricultural Extension Service, Kerrville, Texas, pp. 76-83.

United States Census Bureau QuickFacts, 2016. Retrieved February 16, 2018, from. https://www.census.gov/quickfacts/fact/table/US/AGE775216\#viewtop.

United States Department of Agriculture Animal and Plant Health Inspection Service [USDA-APHIS], 2016, April 6. Retrieved November 8, 2017, from. https://www. aphis.usda.gov/aphis/ourfocus/wildlifedamage/operational-activities/feral-swine.

United States Department of Agriculture Animal and Plant Health Inspection Service [USDA-APHIS] History of Feral Swine in the Americas, 2018, December 4. Retrieved from. https://www.aphis.usda.gov/aphis/resources/pests-diseases/feral-swine/sa-fshistory.

Vaske, J.J., Donnelly, M.P., 1999. A value-attitude-behavior model predicting wildland preservation voting intentions. Soc. Nat. Resour. 12 (6), 523-537.

Vitousek, P.M., Antonio, C.M., Loope, L.L., Westbrooks, R., 1996. Biological invasions as global environmental change. Am. Sci. 84 (5), 468.

Whittaker, D., Vaske, J.J., Manfredo, M.J., 2006. Specificity and the cognitive hierarchy: value orientations and the acceptability of urban wildlife management actions. Soc. Nat. Resour. 19 (6), 515-530. 